\title{
STRUMA OVARII IN A 56-YEAR-OLD WOMAN - A CASE REPORT
}

\author{
Andra M. IONESCU ${ }^{1}$, Bogdan SOCEA ${ }^{2}$, Mihai C.T. DIMITRIU ${ }^{3}$, Vlad D. CONSTANTIN ${ }^{2}$, \\ Cringu A. IONESCU ${ }^{3}$, Alexandra MATEI ${ }^{3}$, Diana C. GHEORGHIU ${ }^{1}$, Irina PACU ${ }^{3}$, \\ Teodora VLADESCU ${ }^{4}$, Mihai B. NICULAE ${ }^{5}$
}

${ }^{1}$ Emergency Clinical Hospital „Sf. Pantelimon“, Obstetrics and Gynecology Department, Bucharest, Romania

2 Emergency Clinical Hospital „Sf. Pantelimon“, General Surgery Clinic, „Carol Davila“ University of Medicine and Pharmacy, Bucharest, Romania

${ }^{3}$ Emergency Clinical Hospital „Sf. Pantelimon“, Obstetrics-Gynecology and Neonatology, „Carol Davila“ University of Medicine and Pharmacy, Bucharest, Romania

${ }^{4}$ Emergency Clinical Hospital "Sf. Pantelimon", Pathology Department, Bucharest, Romania

5 „N. Gh. Lupu“ Clinical Hospital, Pathology Department, Bucharest, Romania

Received 02 Apr 2019, Accepted 17 May 2019

https://doi.org/10.31688/ABMU.2019.54.2.24

\section{Abstract}

Introduction. Struma ovarii represents a rare tumor, only $1 \%$ of the ovarian tumors, with an incidence of $0.3-0.7 \%$. The positive diagnosis is obtained by microscopic examination; sometimes elevated serum levels of thyroid hormone, CA 125 and ultrasound aspects can suggest the preoperative diagnosis.

Case presentation. We report the case of a 56-year-old woman with unilateral struma ovarii and no clinical or paraclinical evidence of the diagnosis to come. Transvaginal ultrasound revealed polyfibromatous uterus and apparently normal adnexa. Partial hysterectomy with bilateral salpingo-oophorectomy (considering the patients age) through laparotomy was performed under spinal anaesthesia. The histopathological result showed an endometrial polyp, multiple

\section{Résumé}

Struma ovarii chez une femme de 56 ans - rapport de cas

Introduction. Struma ovarii représente une tumeur rare, seulement $1 \%$ des tumeurs de l'ovaire, avec une incidence de 0,3 à 0,7\%. Le diagnostic positif est obtenu par examen microscopique; parfois, des taux sériques élevés d'hormones thyroïdiennes, de CA 125 et d'échographies peuvent suggérer un diagnostic préopératoire.

Rapport du cas. Nous rapportons le cas d'une femme de 56 ans avec une struma ovarii unilatérale et aucune preuve clinique ou paraclinique du diagnostic à venir. L'échographie transvaginale a révélé un utérus poly-fibromateux et des annexes apparemment 
intrauterine leiomyomas, left ovary with thyroid follicles, which looked like normal thyroid tissue. The evolution of the patient was favorable, with no complications at the 6 months' follow-up.

Conclusions. In the literature, there are only a few cases of benign struma ovarium, and even less cases of malignant struma ovarium or bilateral presentation of the tumor. The particularity of the case consists in the diagnosis of struma ovarii only after surgery, in a patient without clinical or paraclinical evidence of this diagnosis.

Keywords: struma ovarii, ovarian tumor, malignant.

\section{INTRODUCTION}

Struma ovarii is a mono-dermal teratoma composed predominantly or solely of thyroid tissue ${ }^{1}$. This type of tumor accounts for $3 \%$ of ovarian teratomas ${ }^{2}$. It is encountered in the reproductive age, with most patients being in the fifth decade of life ${ }^{1,3}$. It is found almost always unilaterally, in only $10 \%$ and $15 \%$ being bilateral ${ }^{3}$. It is most commonly asymptomatic, seldom clinically discernable as a palpable pelvic mass and even less frequently associated with ascites $(1 / 3)$ or Meigs syndrome ${ }^{1,2}$. On some occasions, hyperthyroidism is present ${ }^{2}$. High serum levels of CA - 125 have been reported ${ }^{2}$. At ultrasound examination, it can appear complex and nonspecific ${ }^{2,3}$. However, low-resistance blood flow or good vascularized solid component in the central portion are important clues for the diagnosis of struma ovarii.

On gross examination, the tumor has a color that can vary from red to brown and green and a size of no more than $10 \mathrm{~cm}^{1}$. It consists of predominantly solid, soft tissue ${ }^{4}$.

Like the thyroid tissue it emulates, struma ovarii is made of hundreds of thousands of follicles lined by cuboidal or low columnar epithelium ${ }^{5}$. Cytology is usually with minimal atypia and low mitotic activity ${ }^{2}$. One can encounter variants such as the microfolliculae, the pseudotubular or the solid pattern. The latter can be composed of oxyphilic (abundant eosinophilic cytoplasm) or clear cells (pale cytoplasm).

Association with dermoid cysts, mucinous tumours or Brenner tumours has been described ${ }^{2}$. Malignant change in struma ovarii most commonly leads to papillary or follicular carcinoma, but it is normales. Une hystérectomie partielle avec salpingo-ovariectomie bilatérale (compte tenu de l'âge du patient) par laparotomie a été réalisée sous anesthésie rachidienne. Le résultat histopathologique a montré un polype de l'endomètre, de multiples léiomyomes intra-utérins, un ovaire gauche avec des follicules thyroïdiens, qui ressemblait à un tissu thyroïdien normal. L'évolution de la patiente était favorable, sans complication au recul de 6 mois.

Conclusions. Dans la littérature, il n'y a que quelques cas de struma ovarii bénigne et encore moins de cas de struma ovarii maligne ou de présentation bilatérale de la tumeur. La particularité du cas consiste dans le diagnostic de struma ovarii seulement après une poussée, chez une patiente sans preuve clinique ou paraclinique de ce diagnostic.

Mots-clés: struma ovarii, tumeur ovarienne, maligne.

still unclear whether the criteria used in the thyroid gland should be applied ${ }^{1,2}$. Thyroglobulin and TTF1 are essential immunohistochemical markers for a struma diagnosis, with the former being more specific $^{4}$. When suspecting a carcinoid, additional stains such as chromogranin or synaptophysin are useful in differentiating the two entities ${ }^{3}$. Histologic heterogeneity makes the differential diagnosis more difficult. The most important neoplasm a pathologist should exclude are ovarian cystadenoma (when confronted with a cystic struma), steroid cell tumours, carcinoid tumours, Sertoli-Leydig cell tumours, renal clear cell carcinoma, and metastatic melanoma (in case of oxyphilic struma) $)^{2,4}$.

Differential diagnoses include: clear cell carcinoma (primary or metastatic from the kidney), primary or secondary hydatid cyst $^{6}$, metastatic tumors from renal sarcoma ${ }^{7}$, endometrioid carcinomas, Sertoli cell tumour, hepatoid yolk sac tumour, malignant melanoma, serous cystadenoma, pregnancy lutcomas, metastatic thyroid carcinoma of the ovary ${ }^{2,4}$, secondary tumors from retroperitoneum ${ }^{8,9}$, GIST tumors ${ }^{10,11}$, primary ${ }^{12}$ or secondary carcinoid tumors, tumoral or benign appendiceal pathology $y^{13,14}$.

Most often, the prognosis is favourable, with typical struma ovarii being benign ${ }^{1}$. Even in the small percentage of histologically malignant results $5-10 \%$, the outcome is favourable, with only few patients who die of this disease ${ }^{1,2}$. The strumal component, abundant ascites, adhesions and defects of the ovarian serosa are correlated with the malignant type ${ }^{1}$. Only half of the malignant tumors associate extension beyond the ovaries ${ }^{2}$. 
The recommended treatment is oophorectomy and, in case of malignant struma, extraovarian tumor removal is advised ${ }^{2}$.

Patients are advised to have a long-term follow-up².

The aim of this case report is to show the diagnostic stages and treatment of a rare case of struma ovarii, which represents no more than $1 \%$ of all ovarian tumours and $3 \%$ of all dermoid tumors ${ }^{1}$.

\section{Case presentation}

A 56-year-old woman was admitted to the Department of Obstetrics and Gynaecology of "St. Pantelimon" Emergency Clinical Hospital, Bucharest, Romania, on November 2018, for persistent vaginal bleeding during menopause. From the patient's personal history, we noted one birth through C-section in 1994, the occurrence of menopause at the age of 51 years, obesity stage II, fibroadenoma of the left breast with surgical intervention in 2000,

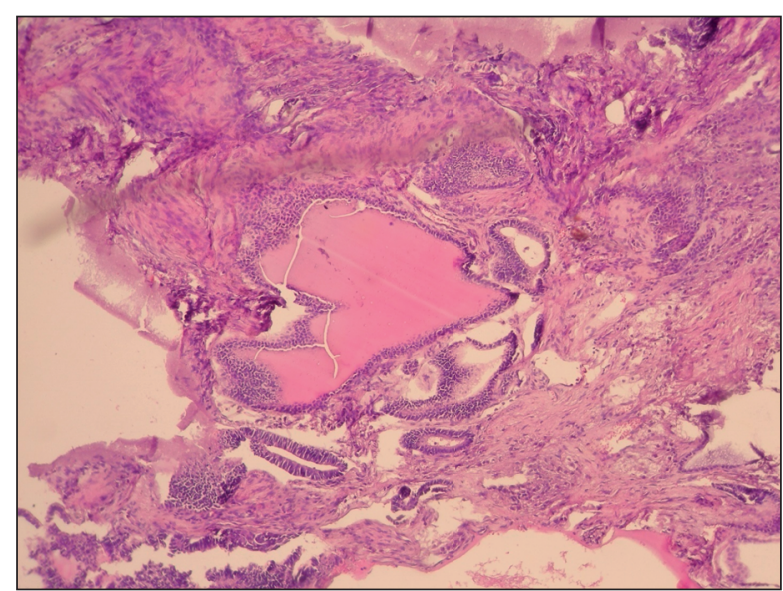

Figure 1. Thyroid tissue: intraovarian colloid. HE staining, $x 4$.

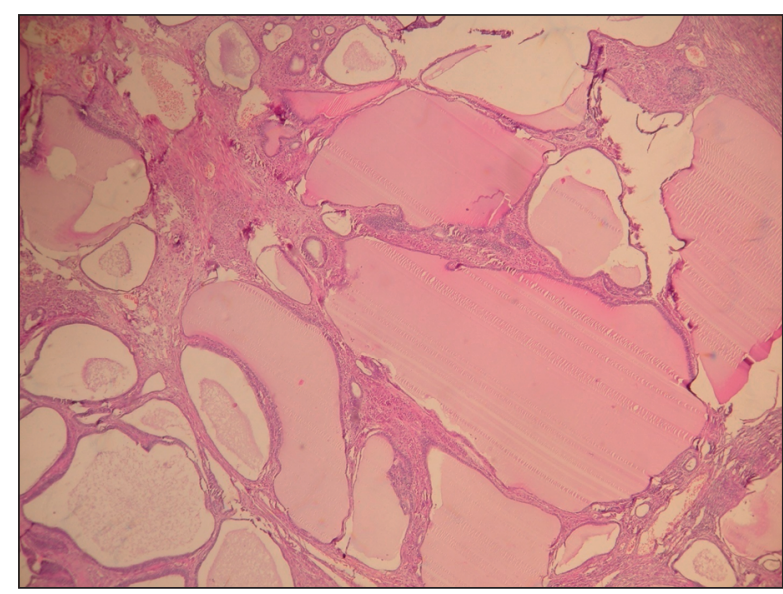

Figure 3. Thyroid follicles in the ovary. HE staining, x20. hypercholesterolemia, hypertriglyceridemia, smoker (20 cigarettes/day). Dilatation and uterine curettage were performed in May 2018, with the histological result of endometrial polyp.

On admission in our department, the patient was cooperative, the blood pressure was $120 / 75$ $\mathrm{mmHg}$, heart rate 73 beats/minute, with moderate vaginal bleeding. The gynaecological examination with the speculum showed no macroscopic lesions on the cervix and moderate bleeding coming from the uterine cavity. On the bimanual examination, the uterus was firm, with increased volume, irregular contour, mobility was preserved, sensitive at mild palpation, bilateral adnexa were normal. Laboratory exams were in normal range. Transvaginal ultrasound was performed and revealed a polyfibromatous uterus and apparently normal adnexa.

The informed consent was obtained and exploratory surgery through laparotomy was performed under spinal anaesthesia (spinal block/ intradural block/ intrathecal block) and followed by partial hysterectomy

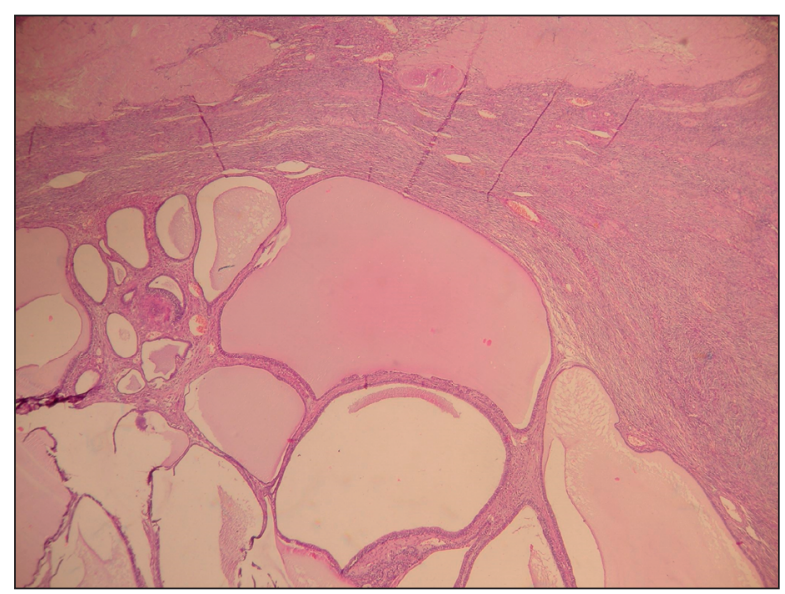

Figure 2. Ovary with corpus albicans and thyroid follicles. HE staining, x10.

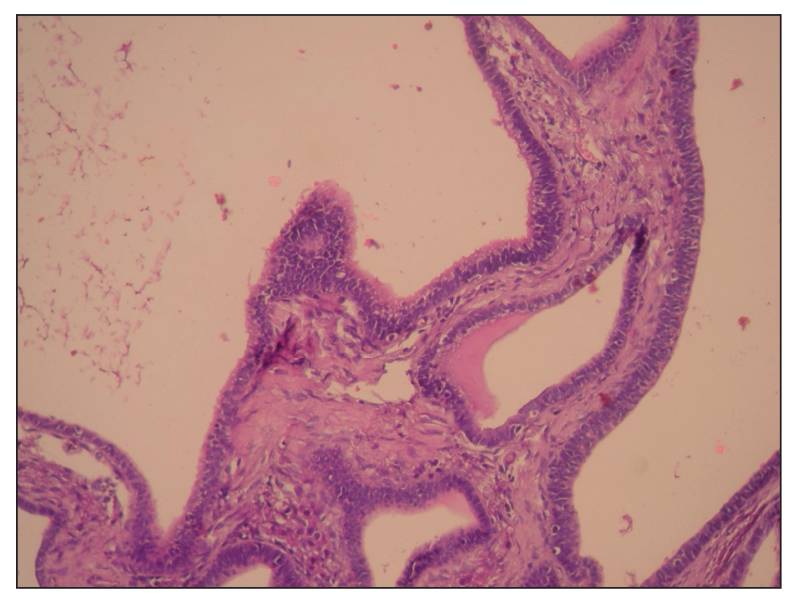

Figure 4. Struma ovarii - thyroid follicles. HE staining, $x 4$. 
with bilateral salpingo-oophorectomy, considering the age and examinations prior to the surgery.

The postoperative evolution was favourable, without any complications. On day 7, the patient was released from the hospital with good general condition and afebrile.

The histopathological result showed an endometrial polyp with glands composed of unistratificate columnar epithelia, some of them cystically dilated, multiple intrauterine leiomyomas, left ovary which showed lobular display and consisted of thyroid follicles, which looked like normal thyroid tissue. The cells were cuboidal to columnar and dense colloid is seen inside the follicles (Figures 1-4). The right ovary was sclera hyalinized and both salpinges were atrophic.

At the 6 months' follow-up of the patient no complications occurred and the laboratory investigations were within normal limits.

\section{Discussion}

The clinical diagnosis of struma ovarii is difficult due to the rarity of the disease. Most of the times the patient is asymptomatic, with no abnormal paraclinical investigations. This is the case of our patient, who had normal serum levels of the thyroid hormones or CA 125, with normal vaginal ultrasound of the ovaries and no ascites. If the preoperative diagnosis occurs, laparotomy surgery is advised, due to the risk of tumor rupture intra-abdominally with dissemination, in case of a malignant tumor.

Oophorectomy is preferred and in case the malignant struma ovarii is confirmed, second intervention is planned and scheduled for pelvic and para-aortic lymph nodes sampling, peritoneal cytologic washing, partial or total omentectomy. Thyroidectomy and follow-up with Iodine-131 whole body scanner are recommended. In some cases, fertility can be preserved as needed and follow-up with the intervention as explained earlier.

The postoperative management of the patients after surgery is difficult, due to the rarity of the cases. Both guidelines of ovarian cancer and thyroid cancer are used.

\section{Conclusions}

The treatment of choice has to be carefully selected because of the high possibility of clinically misdiagnosing this pathology. If the diagnosis is established, laparotomy is advised due to the better accessibility and manipulation of the tumor by the surgeon. Fertility can be preserved, but caution must be implied. The majority of the patients has a good outcome.

\section{Compliance with Ethics Requirements:}

„The authors declare no conflict of interest regarding this article"

"The authors declare that all the procedures and experiments of this study respect the ethical standards in the Helsinki Declaration of 1975, as revised in 2008(5), as well as the national law. Informed consent was obtained from the patient included in the study"

"No funding for this study"

\section{References}

1. Kurman RJ, Carcangiu ML, Herrington CS, Young RH. WHO - Classification of Tumours of Female Reproductive Organs, Volume 6, in WHO Classification of Tumors, WHO ed., 2014.

2. Nucci MR, Oliva E - series editor Goldblum JR. Gynecologic Pathology. In Foundations in Diagnostic Pathology, Elsevier, 2009.

3. Crum C, Hirsch M, Peters III W, Quick CM, Laury A. High Yield Pathology, Gynecologic and Obstetric Pathology Volume, Elsevier, 2015.

4. Clement P, Stall J, Young R. Atlas of Gynecologic Surgical Pathology, 4th Edition, Elsevier, 2019.

5. Ross MH, Pawlina W. Histology - A Text And Atlas, sixth edition, Lippincott Williams \& Wilkins, 2011.

6. Iorga L, Anghel R, Marcu D, et al. Primary renal hydatid cyst - a review. J Mind Med Sci. 2019; 6(1): 47-51.

7. Iorga L, Anghel R, Marcu D, et al. Renal sarcoma - a rare parenchymal tumor with a very poor prognosis. Arch Balk Med Union 2018;53(3):439-444.

8. Bratu OG, Marcu RD, Socea B, et al. Immunohistochemistry particularities of retroperitoneal tumors. Rev Chim (Bucharest) 2018;69(7):1813-1816.

9. Marcu DR, Ionita-Radu F, Iorga LD, et al. Vascular involvement in primary retroperitoneal tumors. Rev Chim (Bucharest) 2019;70(2):445-448.

10. Constantin VD, Socea B, Popa F, et al. A histopathological and immunohistochemical approach of surgical emergencies of GIST. An interdisciplinary study. Rom J Morphol Embryol. 2014; 55(2 Suppl):619-627.

11. Carlomagno G, Beneduce P. A gastrointestinal stromal tumor (GIST) masquerading as an ovarian mass. World J Surg Oncol. 2004; 2:15.

12. Kim HS, Yoon G, Jang HI, Song SY, Kim BG. Primary ovarian carcinoid tumor showing unusual histology and nuclear accumulation of -catenin. Int J Clin Exp Pathol. 2015; 8(5):5749-5752.

13. Socea B, Smaranda AC, Nica AA, et al. Post-colonoscopy acute appendicitis - our case series and a review of the literature. Arch Balk Med Union. 2018;53(4):313-315.

14. Dumitrescu D, Savlovschi C, Oprescu S, et al. A rare complication of acute appendicitis - case presentation. Arch Balk Med Union. 2019;54(1):196-199.

15. Constantin VD, Carap A, Nica A, Smaranda A, Socea B. Appendiceal diverticulitis - a case report. Chirurgia. 2017;112(1):82-84. 